\title{
Bandoleiros, cangaceiros e matreiros: revisão da historiografia sobre o Banditismo Social na América Latina
}

Norberto O. FERRERAS ${ }^{1}$

RESUMO: A questão do Banditismo Social tem sido abordada inúmeras vezes nas sociedades considerando uma alta proporção de população rural. Esta temática ingressou para a História Social por intermédio de Hobsbawm na década de sessenta, e passou a ser freqüentemente analisadas por historiadores. Nos últimos anos, porém, deixou de ser um tema central nessa área. Se esta temática foi tão importante nas sociedades da América Latina, isto se deveu à preocupação inicial das literaturas nacionais da região sobre os tipos rurais e, entre estes, os camponeses revoltados, de forma individual ou coletiva. O objetivo deste artigo é apresentar os estudos atuais na área.

PalaVras-CHaVe: Bandidismo Social; América Latina; História social.

INTRODUÇÃO

O Banditismo Social é uma temática recorrente nas sociedades com forte presença rural, como na América Latina. As literaturas nacionais da região apresentam referências aos tipos rurais e, entre estes, os camponeses revoltados, de forma individual ou coletiva. Entre estas duas formas de resistência, os literatos do século XIX preferiram a individual como modelo. Esses indivíduos revoltados foram a base da construção de arquétipos e, a posteriori, a base de modelos na construção da identidade nacional. Tanto o romantismo quanto o liberalismo analisaram este tipo social como a base da nacionalidade: pessoas violentas lutando contra o irreversível avanço da modernidade, identifi- 
cadas com os valores patriarcais tradicionais e associadas à liberdade absoluta do bom selvagem.

Se analisarmos a América Latina segundo fatores étnicos, teremos que a presença das etnias autóctones pesou na hora da definição do caráter dos homens do campo. Nos locais em que predominaram os indígenas e os escravos, os brancos descendentes de espanhóis, colocaram-se como modelo, como aconteceu no México, Chile e Peru, por exemplo. Os indígenas foram menosprezados pela falta de aceitação da cultura européia. Nas regiões em que os indígenas não eram o elemento principal da população e, portanto, onde o perigo da miscigenação foi menor, o criollo americanizado foi o elemento principal na conformação de uma identidade nacional, de forma positiva ou negativa, como na Argentina.

\section{COMO SE CONSTRÓI UM MITO: O CASO DA ARGENTINA}

Para compreender a construção destas identidades vamos apresentar o caso argentino. Durante grande parte do século XIX a política argentina esteve condicionada pela dominação de Juan Manuel de Rosas. Contra Rosas escreveram os principais literatos daquele país, até a década de 1870. José Marmol, Esteban Echeverria, Bartolomé Mitre, Domingo Faustino Sarmiento e outros foram extremamente críticos ao potencial do gaucho para se tornar o modelo da nacionalidade. Para eles, o gaucho representava os valores contrários à modernidade européia. O romantismo desses autores baseou-se na necessidade da dominação dos elementos da natureza, dentre os quais o homem do campo. $^{2}$

O romantismo argentino, nos seus momentos finais, inverteu seus valores, resgatando a figura do gaucho, que deixou de ser um elemento a mais na natureza, para passar a organizar a identidade nacional. As levas de imigrantes que começavam a chegar ao Rio de la Plata foram vistas como desintegradoras da comunidade nacional, e o gaucho, oposto aos gringos, cobrou uma nova dimensão. Para Sarmiento, a natureza se expressava nos homens do campo e, deste modo, o projeto de mo- 
dernização liberal devia ser executado para que a Argentina se incorporasse à divisão internacional do trabalho. No fim do romantismo as urgências eram outras. Para eles, que aproveitavam as reformas liberais da geração anterior, a ênfase passou a estar na construção de uma identidade à prova dos imigrantes. O gaucho apareceu como um elemento disponível nesta operação, pelo que os motivos e as figuras populares emergiram nesse romantismo tardio e perduraram por décadas numa corrente literária chamada de gauchesca. Paradoxalmente, quase todos os tipos valorizados pela gauchesca eram homens em conflito com a lei. Eles estavam lutando contra a modernidade liberal e as formas culturais e políticas a ela associadas.

Os romances protagonizados por esses heróis tornaram-se best sellers populares. Vendidos na zona rural e lidos ritualmente, alcançaram o seu objetivo: ser uma literatura que retratava e representava os tipos populares. Alguns destes heróis cumpriram fielmente os objetivos dos seus autores. O mais difundido foi o poema épico de José Hernández Martín Fierro e a sua saga. ${ }^{3}$ Na primeira parte, o autor retrata as desventuras de um gaucho na luta para ser independente num mundo em transformação. Implacável com os estrangeiros, e com aqueles que ameaçavam a sua segurança, ele foge em direção à fronteira com outro rebelde, Cruz, depois de assassinar um negro numa festa. Na segunda parte, mostra-se o arrependimento de Fierro por abandonar sua família e ter vivido entre os índios. Os conselhos aos seus filhos são um ponto de inflexão no seu comportamento, representando a incorporação resignada do gaucho na nova ordem dos pampas.

No mesmo ano da publicação do Martín Fierro, apareceu o Santos Veja, de Hilario Ascasubi, e em 1879, junto com O retorno..., veio à luz Juan Moreira, de Juan María Gutierrez. Ambos são narrativas de gauchos rebeldes que se tornam bandidos contra a sua vontade e pela defesa da honra. Ambos são os últimos gauchos rebeldes a povoar a literatura gauchesca e a aparecer como modelos alternativos ao cada vez mais hegemônico projeto da civilização de Sarmiento. A barbárie, daqui em diante, estará derrotada, e os gauchos passaram a ser modelos de virtude moral para o homem da cidade, como acontece no roman- 
ce que fechará este ciclo: Don Segundo Sombra, de Ricardo Güiraldes, de $1926 .{ }^{4}$

A revalorização do gaucho continuará ao longo do século XX. Até aqueles grupos identificados com a modernidade uniram os valores do seu próprio discurso com elementos populares provenientes da gauchesca, de reconhecida eficiência na mediação entre os mundos rural e urbano. Este é o caso dos anarquistas que, nas suas publicações destinadas aos homens das zonas rurais, usaram e abusaram da figura dos gauchos e, especificamente, daqueles que podemos identificar como bandidos sociais, para elaborar metáforas sobre o avanço do capital, e as conseqüências para os pequenos proprietários e para o proletariado rural, como podemos ver a seguir:

Juan Moreira

Juan Moreira es el gaucho altivo y digno que, despojado de sus tierras, sus animalitos y hasta de su china, por el capitalismo invasor y la policía de su servicio, se yergue cuchillo en mano, magnifico por el coraje, frente a los opresores y pelea sin dar ni pedir cuartel hasta morir, por su dignidad radiante de belleza, por la dignidad de los muchos robados y engañados y encarcelados de mil maneras.

El era el dueño primitivo de estas heredades, el dueño legítimo, por derecho natural (...) Pero el capitalismo avasállalo todo, colocando mojones y alambrados desterrando el habitante auténtico a los montes, a las orillas de las cañadas o a un rincón del campo y sembrando taperas por el camino como nidos vacíos.

Moreira es el prototipo del rebelde instintivo contra el capital trashumante y contra el servilismo de sus congéneres, en una época en que la solidaridad de clase, en que la lucha de clases no estaba definida.

(...) Moreira es él y nadie más.

(...) Es el prototipo del rebelde instintivo, que bien puede servir de base de un estudio: desde Juan Moreira al "linghera" de hoy. ${ }^{5}$

É neste mesmo período que alguns grupos anarquistas deixaram a tarefa da organização e retomaram a ação direta, criando grupos de bandidos sociais, principalmente urbanos, como o liderado por Seve- 
rino di Giovanni, ou rurais, como o Soviete Vermelho que atuou na $\mathrm{Pa}$ tagônia durante as greves de 1921 a $1923 .{ }^{6}$

O bom rebelde, o gaucho, que depois de sofrer inúmeras injustiças acabava se levantando e resistindo aos avanços do capital ou das forças da modernização, passou a ser incorporado ao imaginário popular.

As fontes para o Banditismo Social são vastas e numerosas. Neste artigo apresentaremos a forma em que se constituiu este campo de estudos e em que estado estão os debates sobre o Banditismo Social na América Latina.

A CONSTRUÇÃO DE UM CAMPO DE ESTUDOS:

A INVENÇÃO DO “BANDIDO SOCIAL”

Desde a década de 1960, as aproximações da História Social ao fenômeno do Banditismo Social estiveram fortemente marcadas pelos estudos desenvolvidos por Eric Hobsbawm. Fernand Braudel tinha feito alguns avanços nesta questão, porém, só quando Eric Hobsbawm publicou Primitive Rebels, em 1959, e Bandits em 1969, o Banditismo Social, como uma forma de resistência camponesa, passou a fazer parte do elenco temático da História Social. ${ }^{7}$ Este modelo de análise foi aplicado largamente a distintas realidades e situações, com maior ou menor êxito. Desde o início, este é um tema que aparece como necessariamente comparativo e não restrito a um período histórico e, outrossim, a uma determinada situação histórica.

Segundo Hobsbawm, o Banditismo Social é um fenômeno universal, dado que os camponeses teriam todos eles um modo de vida similar, definido pelo acesso direto à terra e a uma série de recursos naturais e de reciprocidades costumeiras na comunidade; por isto, o Banditismo Social não tem um período definido numa cronologia unívoca. Conforme Hobsbawm, a transição para o capitalismo agrário não acontece num momento histórico específico e depende do momento em que se produz essa transição. Nos países desenvolvidos, esta passagem aconteceu no século XVIII, enquanto nas sociedades da América 
Latina, no século XX. O momento em que começa o Banditismo Social pode não estar muito bem definido, mas está associado à desintegração da sociedade tribal ou à ruptura da sociedade familiar. É evidente que o Banditismo Social acaba com a difusão do capitalismo industrial e com a consolidação do Estado Nacional, estando relacionado à emergência das classes, e da luta de classes que dão uma nova orientação às lutas dos camponeses.

A análise de Hobsbawm baseia-se na existência de três tipos de bandidos: o bandido nobre, como Robin Hood; os guerrilheiros primitivos; e o vingador, como Lampião. Estas formas diferem segundo as regiões em que o Banditismo Social se desenvolveu, e que não devem ser confundidas com as práticas de comunidades que têm no crime uma forma de vida não diretamente relacionada com a transição para o capitalismo. Se os bandidos alcançam uma certa notoriedade - e em outros locais não temos registros destes grupos - isto se deve à influência de alguns fatores, como as crises políticas e econômicas da região, as estruturas do poder local e o poder dos proprietários.

$\mathrm{O}$ que faz com que estes movimentos de camponeses continuem a ser mais uma das formas de expressão de descontentamento, ou se transformem em movimentos revolucionários, depende de fatores externos. Estes fatores estão relacionados com crises do tipo estruturais, que podem ser provocadas por catástrofes naturais ou por fenômenos irreversíveis, como a emergência do capitalismo. De acordo com Hobsbawm, é nestas ocasiões que o Banditismo Social pode passar a vincular-se a movimentos revolucionários, ou a aceitar a liderança de líderes revolucionários. ${ }^{8}$

Outros dois elementos do modelo de Hobsbawm merecem ser lembrados. Primeiro, temos que destacar a capacidade que seu modelo tem para definir quem estava apto a integrar-se aos grupos de bandidos, o que é uma excelente análise da sociedade camponesa. Não é qualquer um que podia tornar-se um bandido. $O$ bandido não podia ter relações familiares que o apressassem a poder ingressar nessa nova vida, e ao mesmo tempo a sua ligação familiar tinha que ser suficientemente forte para que, uma vez empreendida essa nova atividade, servisse para proteger ou favorecer seu grupo familiar. Em segundo lugar, 
para formular seu modelo, Hobsbawm baseou-se no folclore e nas narrativas dos feitos desses bandidos. Porém, estas narrativas apareceram reformuladas posteriormente ao desaparecimento dos bandidos, e adaptadas à novas situações.

Desde o momento em que Hobsbawm formulou a sua aproximação ao Banditismo Social, ele sofreu uma série de críticas sinalizando certas dificuldades. O primeiro a questioná-lo foi Anton Blok, especialista no assunto, que em 1972 mostrou as dificuldades existentes no modelo de Hobsbawm que pensava no banditismo como "social", e as simplificações a que foram submetidos os casos escolhidos para construir o modelo. ${ }^{9}$ Blok partiu das suas próprias pesquisas sobre o banditismo para dizer que Hobsbawm apelava a generalizações excessivas nas suas análises. O tipo de fontes utilizadas leva implícita uma avaliação positiva do fenômeno, romantizado pelos camponeses e por alguns pesquisadores. Outro questionamento diz respeito ao interesse pelo protesto social, antes que pelos casos em si, e desta forma acabam sendo silenciados outros aspectos da relação camponeses-bandidos, como a utilização da violência contra os camponeses. As fontes e o mito são centrais na análise de Hobsbawm e ambos são questionados por Blok.

Blok asseverou que o Banditismo Social foi muitas vezes um banditismo anti-social, dado que os camponeses foram muitas vezes vítimas dos bandidos, preocupados primeiro em atender a seus vínculos com os poderosos locais, do que com os camponeses. O autor levantou uma agenda temática para aprofundar estes estudos, preferindo os casos ao modelo. Para isto sugeriu analisar o mundo rural como um todo, a fim de compreender as relações sociais existentes, o que tornaria mais compreensível a opção pelo banditismo. Anton Blok nos chama a atenção sobre as limitações do Banditismo Social para o desenvolvimento de formas coletivas de protesto, em virtude das possibilidades abertas às carreiras individuais.

Hobsbawm entendeu que as críticas de Blok não feriam seu modelo. De fato, em razão das críticas realizadas por Blok, Hobsbawm afirmou que o mito do Banditismo Social tinha que ser analisado, desconsiderando a base do argumento de Blok e reforçando sua posição. ${ }^{10}$ Hobsbawm continuou a ser a principal influência para estudos poste- 
riores. O influxo das suas hipóteses tem se mostrado irresistível para as gerações seguintes de historiadores.

Depois de alguns trabalhos que seguiram à risca as análises de Hobsbawm, apareceram algumas críticas em periódicos especializados: um destes estudos pode ser considerado como de transição, e Peter Singelmann publicou um artigo sobre cangaceirismo como Banditismo Social, que pretendia reforçar os argumentos de Hobsbawm no debate com Blok. ${ }^{11}$ Levantou questões próprias do modelo de Hobsbawm, principalmente no recrutamento do bandido. Mas as diferenças são importantes. Singelmann não estava interessado no mito do Banditismo Social, mas nas implicações políticas do cangaceirismo, e para isto analisou a farta bibliografia sobre o coronelismo como sistema político e o cangaceirismo como uma forma de oposição ao mesmo. Simultaneamente, ele próprio estabeleceu uma continuidade entre cangaceirismo e coronelismo, como um caminho de mão dupla, fosse na rota da ascensão social, fosse no caminho à oposição política, forçado pela mudança de ventos na política nacional ou regional.

As críticas mais fortes vieram poucos anos depois com as pesquisas de um outro grupo de historiadores. Em 1987 foi publicado nos Estados Unidos um livro que, em inglês, tinha o sugestivo título de Bandidos, em referência ao Bandits de Hobsbawm. Hobsbawm era a referência óbvia para este grupo, mesmo que fosse para interpelar as suas propostas. Richard Slatta, editor e autor, aceitou as dificuldades de lidar com o mito. ${ }^{12}$ Slatta na introdução apontou duas questões que mostravam uma importante diferença da proposta de Hobsbawm: as fontes e a importância das classes médias na construção do mito do banditismo. Sobre a primeira questão, este livro nos proporciona uma renovação importante, trazendo á tona o material produzido pelas polícias regionais e pelo poder judiciário na perseguição aos bandidos. E quanto à segunda, a preocupação centrou-se nas interpretações que as classes médias urbanas fizeram do Banditismo Social. ${ }^{13}$

Os artigos deste livro preocuparam-se com a diversidade do Banditismo Social na América Latina, abordando os bandidos mexicanos do século dezenove, o cangaceirismo no nordeste do Brasil, o banditismo rural argentino e venezuelano, as relações entre banditismo e co- 
munidades camponesas nos Andes. Este livro apresenta, ainda, outras aproximações como as recreações que Hollywood realizou dos bandidos e os estudos realizados pelos criminalistas latino-americanos.

Nas conclusões deste livro, Slatta afirma que é impossível falar de Banditismo Social na América Latina. Estas afirmações resultam da constatação de uma das premissas de Blok: as relações existentes entre os bandidos e as elites rurais regionais dificultam, decididamente, a possibilidade de que o bandido se torne um herói popular ou um defensor dos pobres. Slatta entende que seria preciso utilizar outra terminologia, como bandidos nas guerrilhas ou banditismo político. $\mathrm{O}$ banditismo, então, não seria um movimento pré-político, e sim um grupo com objetivos complexos, podendo ou não estar prontos a transformar a sociedade. Entre as motivações estariam a luta contra a opressão, mas também por benefícios pessoais. Os bandidos sociais certamente estariam interessados em si próprios, e alguns chegariam a ser aceitos novamente na sociedade civil sem maiores inconvenientes. Os rasgos próprios do Banditismo Social, como a distribuição dos roubos entre os camponeses, seriam funcionais às necessidades dos bandidos, antes que um ato de reparação. ${ }^{14}$

Ante esses argumentos parece difícil continuar a analisar o Banditismo como Banditismo. Mas as reações à análise desse grupo de historiadores não demoraram, e as respostas geraram um intenso debate. O primeiro a se manifestar foi Gilbert Joseph, que não deixou de questionar as principais fontes desse grupo, as fontes oficiais, que acabam sendo parciais, remarcando certos aspectos do banditismo. Joseph também propôs reexaminar as relações sociais nas regiões rurais e as formas da resistência camponesa. Nem todo roubo é um ato de resistência, e ainda a resistência pode estar fora dos grupos de bandidos e em elementos do cotidiano, como pequenos furtos ou apropriações de elementos das classes proprietárias. Estas formas de luta contra os senhores locais mostram que os camponeses tiveram uma tendência ao compromisso maior do que a prevista, e que a baixa intensidade dos conflitos de classe permitem uma convivência relativamente pacífica. A proposta de Joseph retoma a necessidade de analisar o papel das classes médias na criação do mito do Banditismo Social. Ao mesmo tempo, ex- 
pressa a necessidade de definir novamente o que é o Banditismo Social, em lugar de rejeitá-lo como propunha Slatta. ${ }^{15}$

A resposta de Slatta e de outros foi rápida. No número seguinte da mesma revista, Slatta reafirmou as suas posições, mas admitiu a possibilidade de que os camponeses ajudassem os bandidos. Quando isto acontecia, o apoio era dado por causa das relações de parentesco, amizade ou vizinhança. Sobre a forma de definir o conceito de "Banditismo Social", Slatta optou por uma solução própria da história social, fugiu dos questionamentos foucaultianos de Joseph e partiu para o empirismo, fazendo uma análise de caso. ${ }^{16}$ Outro historiador que respondeu ao artigo de Joseph foi o já citado Peter Singelmann, defendendo as posições de Hobsbawm sem fazer outros aportes ou críticas a Joseph, e aparecendo mais receptivo que Slatta sobre a possibilidade de reexaminar o conceito de Banditismo Social. ${ }^{17}$ A tréplica de Joseph concentrou-se na necessidade de redefinir a terminologia e os conceitos aplicados à análise do Banditismo Social. ${ }^{18}$

Os debates sobre esta questão não estão concluídos, porém têm sido raras as aproximações em que se tentou uma conceitualização desta temática. De alguma forma a posição de Slatta tem sido a predominante, e não só nestes estudos, a História Social parece ter privilegiado as abordagens empíricas e deixado a teoria de lado.

\section{AS POSSIBILIDADES DOS ESTUDOS SOBRE O BANDITISMO SOCIAL}

O que mais se evidencia depois destes anos de debate diz respeito a continuar chamando o Banditismo de "Social", e parece mais interessante pesquisar as causas da violência rural que discutir a existência de um componente de oposição entre "senhor" e "bandido". O mundo rural é de uma complexidade maior que aquela criada pelos escritores das classes médias urbanas para os surtos de bandoleirismo, e neles o Banditismo Social aparece como um fato do passado, todavia, o banditismo contemporâneo aparece como criminalidade. São poucos os 
casos em que o bandido é glorificado em vida, e esta pode ser uma clave para nos aproximarmos desta questão.

Há pouco tempo Paul Saint Cassia publicou um artigo sobre o "banditismo" na Enciclopédia Européia de História Social. O autor caraterizou o banditismo por regiões, inclusive o banditismo na América Latina, ressaltando a dimensão comparativa da questão. ${ }^{19}$ Este artigo aponta para os elementos recorrentes do banditismo, enfatizando a sua dimensão antropológica na construção de um novo modelo. Mas não deixa de chamar a atenção sobre as três possibilidades de abordagem do Banditismo: como uma categoria legal, como uma categoria social, e da perspectiva da lenda e da literatura, popular ou não. Estas três abordagens mudaram com o tempo e de disciplina em disciplina. A maioria dos autores analisados no ponto anterior realizou chamados ao estudo das condições sociais, políticas e econômicas em que se desenvolveu o Banditismo Social. Por outro lado, poucos autores empreenderam esta tarefa, e quase todos se concentraram na discussão do mito do bandido social, mas não podemos descuidar de outros aspectos. A criminalização - ou não - do banditismo está relacionada à forma com que o Estado se defrontou com a questão. Em algumas ocasiões, os bandidos passaram a fazer parte de grupos legais, ou passam a integrar as milícias do Estado (como foi o caso do mexicano Pancho Villa), ou sendo anistiados quando se combateram do lado das forças da lei, como foi oferecido a Lampião para lutar contra a Coluna Prestes.

Segundo Saint Cassia, há vários elementos que estão na base do Banditismo: a estrutura social e a ecologia política da região; a distribuição de propriedades; a acumulação de capital e as formas em que a mesma se legitima; a presença ou ausência da sociedade civil; a existência de um sistema eleitoral confiável unido ao uso da força para impor os resultados; e a insegurança constante, maior que a miséria em que vivem os camponeses. $\mathrm{O}$ autor apresenta um interessante modelo para abordar a questão, contudo nenhum dos pontos por ele apresentados menciona a resistência dos camponeses à opressão. Este modelo está destinado a compreender a existência de uma violência endêmica em certas regiões em que o capitalismo se torna o modo de produção principal. O banditismo e outras formas de protestos rurais são meno- 
res, ou inexistentes, em locais onde o proletariado rural se organiza segundo os padrões trabalhistas, como ligas camponesas ou sindicatos. Se acompanharmos os pontos anteriormente citados poderemos compreender melhor os conflitos rurais na consolidação do capitalismo.

Saint Cassia não esquece as questões culturais do banditismo. Assim, a questão da violência, que tanto preocupara Hobsbawm e Blok, adquire para ele novas tonalidades: A violência é intrínseca ao banditismo? Lampião era um vingador e não um bandido social, porque abusava do uso da violência? Conhecendo a sociedade e a sua cultura, pode-se descobrir se a violência é necessária ou não, se a extrema crueldade de certos bandidos está relacionada com a sua escassa inserção no meio em que atuam, ou se é intrínseca às formas locais da apropriação das riquezas? O uso da violência é um discurso numa linguagem que deve ser interpretada. Saint Cassia chama a atenção para as diferenças entre a "violência" e o "terror", sendo a primeira um tecido de signos e o segundo um dos resultados dos mesmos.

Os aspectos econômicos do Banditismo não têm recebido uma atenção adequada. $\mathrm{O}$ bandido pode ser visto ainda como uma forma de ascensão social e econômica, uma forma de defesa das propriedades familiares, ou reagindo às transformações produtivas. $\mathrm{O}$ bandido também pode ser um agente intermediário nas relações econômicas regionais, atuando por conta própria ou a mando dos poderosos regionais. $\mathrm{O}$ bandido está inserido na economia regional, e para manter boas relações com uma parte dos agentes econômicos tem que pagar pelos serviços recebidos. $\mathrm{O}$ mais importante destes serviços é a proteção, sendo que o pagamento pela proteção era feito em bens e serviços, atuando a mando dos 'coiteiros'. Este não é um assunto menor e nos permite entender a questão da cumplicidade ou os serviços realizados para os poderosos locais.

ABERTURAS A NOVAS PROBLEMÁTICAS E CONCLUSÕES

O Banditismo Social deixou de estar em pauta. Depois do debate na $L A R R$, já mencionado, as abordagens acadêmicas foram decrescen- 
do. Desde meados da década de noventa há menos artigos destinados a analisar esta questão. Em compensação, cresceram os estudos sobre o setor rural, ou as formas em que se manifestou a insatisfação camponesa. No Brasil, a atuação do Movimento dos Sem Terra (MST) ajudou a mudar a maneira como os camponeses eram apresentados, e a historiografia está começando a privilegiar as formas coletivas de ação, ao invés das práticas individuais.

Em outros países a historiografia também passou a priorizar práticas coletivas. Voltemos ao caso da Argentina. Nos últimos anos foram publicados neste país dois livros sobre um mesmo acontecimento: a matança de "gringos" em 1872, na cidade de Tandil, a 400 quilômetros a sudeste da cidade de Buenos Aires. ${ }^{20}$ Os autores abordaram a questão de ângulos diferentes. Para compreender o massacre, John Lynch apresenta a estrutura social, política e econômica da Argentina. O trabalho enfatiza a relação entre gauchos e imigrantes, e as reações posteriores à matança, principalmente das coletividades estrangeiras e do governo inglês. Lorenzo Macagno, por sua vez, centra-se na questão religiosa de um grupo de indivíduos que se sentia expulso da sua sociedade. $\mathrm{O}$ cristianismo primitivo foi a forma de processar estas mudanças e os recém-chegados foram identificados e responsabilizados por essas mudanças.

Ambos os estudos diferem. Macagno carateriza este movimento como messiânico e analisa as suas semelhanças com outros movimentos similares. Lynch, por sua vez, parte das fontes oficiais e daquelas produzidas pelos imigrantes. O interessante em ambos é que o líder principal do bando, Gerónimo de Solané, analisado exaustivamente em ambos os casos, não é visto como um rebelde ou um vingador, e sim como um membro exótico dessa mesma comunidade. É possível entrever semelhanças com outras lideranças religiosas, porém os seus seguidores não são famílias de camponeses, e sim indivíduos fora-dalei. Alguns prófugos do exército, da justiça, desempregados e trabalhadores, formaram em suas filas. Isto nos remete ainda à questão das fontes. As diferenças estão fortemente relacionadas com as fontes escolhidas e as análises realizadas. Ambas se aproximam da questão para entender como esses grupos vivenciaram o processo de modernização do 
campo e, no caso, violência e criminalidade são fundamentais neste processo.

O mito dos bandidos sociais não precisa de justificativas acadêmicas e continua a correr solto. No Brasil são inúmeros os livros, artigos jornalísticos, programas de TV, cordéis e outros, lançados ano a ano. Eles enfatizam a compreensão da personalidade dos principais cangaceiros e a justificativa de uma vida violenta numa sociedade igualmente violenta e injusta. Em março de 2003 foi noticiada a restauração dos filmes e fotografias realizada por Benjamim Abrahão, o que deu uma nova oportunidade para que a questão voltasse a ser apresentada na mídia. Os jornais de Fortaleza enfatizaram o fato e novamente reapareceu o mito do cangaceiro como um homem que resiste às autoridades e luta pela melhoria das condições de vida dos homens do sertão. Novamente o mito e a lenda voltaram à tona. Há uma necessidade de reler sobre o cangaço para afirmar a identidade nordestina. ${ }^{21}$

Poderíamos dizer que Hobsbawm continua a inspirar os trabalhos relacionados com o Banditismo Social, e também podemos questionar as suas abordagens. O que não podemos deixar de reconhecer é a sensibilidade deste autor de compreender a sobrevivência do mito e a forma em que o mito é autonomizado da sua realidade pelos intelectuais das classes médias urbanas. O exemplo citado dos jornais de Fortaleza não deixa lugar a dúvidas: Hobsbawm ainda continua a ser uma referência se abordamos a "invenção" da lenda do Banditismo Social.

FERRERAS, N. O. Bandoleiros, cangaceiros e matreiros. Social Banditism historiography in Latin America reviewed. História. São Paulo, v. 22, n.2, pp. 211-226, 2003.

A BSTRACT: Social Banditism is an important topic in societies with a large number of peasants. There are a large number of researches in this area. These topics come to Social History with the former studies of Eric Hobsbawm, in the sixties, and were frequently analyzed by other historians. The interest in this topic decayed in last years. If this thematic was so important in Latin American societies, was because the former interest of the national literature in rural characters, and special in revolted 
peasant. The objective of this article is to discuss actual studies in this field of research.

KEYWORDS: Social Banditism; Latin America; social History.

\section{NOTAS}

${ }^{1}$ Departamento de História - UFF - CEP 24210-350 - Niterói - RJ. Agradeço a Michael Hall pelas várias indicações bibliográficas; a María Verónica Secreto, pelos comentários e indicações bibliográficas.

${ }^{2}$ Echeverría, Marmol, Mitre, Sarmiento e outros não foram unicamente escritores, também atuaram como políticos, e suas obras estão vinculadas à sua ação como tais.

${ }^{3}$ HERNÁNDEZ, J. Martín Fierro (1872) e El retorno de Martín Fierro (1879). Buenos Aires: Santinllana, 2000. As datas entre parênteses referem-se à primeira edição.

${ }^{4}$ Uma análise interessante sobre esta mudança na visão do gaucho está em SARLO, B. Respuestas, Invenciones y desplazamientos. In:__. Una modernidad periférica: 1920 y 1930. Buenos Aires: Nueva Visión, 1988.

${ }^{5}$ Periódico anarquista La Pampa Libre. Año 2, n. 21, 1ํ de Julio de 1923, General Pico - Territorio Nacional de La Pampa. Linghera ou linyera era o anarquista errante que distribuía panfletos aos trabalhadores rurais; tapera: é uma cabana; e china: é um apelativo afetuoso para a mulher.

${ }^{6}$ Vide BAYER, O. Los anarquistas expropiadores. Buenos Aires: Legasa, 1986.

${ }^{7}$ HOBSBAWM, E. J. Primitive Rebels. Studies in Archaic forms of Social Movements in the $19^{\text {th }}$. and $20^{\text {th }}$. Centuries. Manchester, Manchester University Press, 1974 ( $1^{\mathrm{a}}$ ed. em inglês: 1959); e Bandidos. Rio de Janeiro: Forense Universitária, 1976 ( $1^{\underline{a}}$ ed. em inglês: 1969). E, ainda, BRAUDEL, F. O Mediterrâneo e o Mundo Mediterrânico. Lisboa: Publicações Dom Quixote, 1995, v. II, pp. 96 a 118 (1ª ed. em francês: 1966).

${ }^{8} \mathrm{O}$ modelo de Hobsbawm está desenvolvido na Introdução do livro de HOBSBAWM, E.J. Bandidos... Op. cit.

${ }^{9}$ BLOK, A. The peasant and the brigand: Social Banditry reconsidered in: Comparative studies in Society and History. Cambridge: Cambridge University Press, v. 14, n. 4, September 1972.

${ }^{10}$ HOBSBAWM, E. J. Social Bandits: Reply in: Comparative studies in Society and History. Cambridge: Cambridge University Press, v.14, n.4, September 1972. 
${ }^{11}$ SINGELMANN, P. Political structure and Social Banditry, in Northeast Brazil. In: Journal of Latin American Studies. Cambridge: Cambridge University Press, v. 7, part 1, May 1975, pp. 59- 83.

${ }^{12}$ SLATTA, R. (Ed.). Bandidos. The varieties of Latin American Banditry. New York: Greenwood Press, 1987.

${ }^{13}$ _. Introduction to Banditry in Latin America. In: SLATTA, R. (Ed.). Op. cit.

${ }^{14}$ _. Conclusion: Banditry in Latin America In: SLATTA, R. (Ed.). Op. cit.

${ }^{15}$ JOSEPH, G. On the trail of Latin American Bandits: A reexamination of Peasant Resistance. In: Latin American Research Review. New Mexico: University of New Mexico, v. XXV, n. 3, 1990.

${ }^{16}$ SLATTA, R. Bandits and rural Social History: A comment on Joseph. In: Latin American Research Review. New Mexico: University of New Mexico, v. XXVI, n. 1, 1991.

${ }^{17}$ SINGELMANN, P. Establishing a Trail in the Labyrinth. In: Latin American Research Review. New Mexico, University of New Mexico, v. XXVI, n. 1, 1991.

${ }^{18}$ JOSEPH, G. "Resocializing” Latin American Banditry: A Reply. In: Latin American Research Review. New Mexico, University of New Mexico, v. XXVI, n. 1, 1991.

${ }^{19}$ SAINT CASSIA, P. Banditry. In: Encyclopedia of European Social History. New York, Scribner's, 2001., v. III.

${ }^{20}$ Os livros são LYNCH, J. Masacre en las Pampas. La matanza de inmigrantes en Tandil, 1872. Buenos Aires: Emecé, 2001 (1ª ed. em inglês: 1998); e MACAGNO, L. Apocalipsis al Sur. Una protesta contra inmigrantes en el "desierto" argentino. Buenos Aires: Biblos, 2002.

${ }^{21}$ Seu Nome é Virgulino... In: Diário do Nordeste. Fortaleza, 16 mar. 2003. Caderno 3, p. 1; e A neta de Virgulino e o filho de seu Chico. In: Jornal O Povo. Fortaleza, 20 mar. 2003. Caderno Vida e Arte, p. 1.

Artigo enviado em 06/2003. Aprovado em 08/2003. 